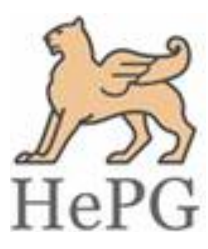

ISSN: 2348-1900

Plant Science Today

http://www.plantsciencetoday.online

Research Article

\title{
Lehya formulations for mother and child care in Havyak community of Uttara Kannada district, Karnataka, India
}

\author{
Shruti V Hegde*, Pradeep Bhat \& Ganesh R Hegde \\ PG Department of Studies in Botany, Karnatak University, Dharwad 580 003, India
}

\section{Article history}

Received: 28 June 2019

Accepted: 21 August 2019

Published: 01 October 2019

\section{Publisher}

Horizon e-Publishing Group

\author{
*Correspondence \\ Shruti Hegde \\ 竞egde.shruthi1@gmail.com
}

\begin{abstract}
The period between pregnancy and the child birth is a critical phase in the lives of mothers and newborn babies. In most of the Asian countries including India, the use of medicinal plants, cultural traditions and the diets practiced by the ethnic groups have their age old histories. Present study was carried out to compile the traditional knowledge of the age old practitioners on pre and postnatal remedies. The survey was carried out in the areas of Sirsi, Siddapur and Mundgod taluks of Uttara Kannada district, Karnataka state, India. Medicinal plants were collected and quantitative data analyses like Use Value (UV), Relative frequency citation (Rfc) and Family Importance Value (FIV) have been provided to analyze the importance of reported plants. The study revealed the use of 28 plant species belonging to 19 families. The home remedies for pregnant women are in the form of paste, called 'Lehya' in local language. Habitwise analysis of the plants indicate that herbs are highly used (35.71\%) and in most of the case fruits (32.14\%) and seeds (25\%) are frequently used plant parts in 'Lehya' preparation. The most important plant species according to the quantitative data analysis are Cassia sophera, Centella asiatica, Cocos nucifera, Cucumis melo var. acidulus, Curcuma longa, Phoenix dactylifera and Syzygium aromaticum.
\end{abstract}

Keywords: Prenatal; Postnatal; Mother care; Child care; Medicinal plants

Citation: Hegde SV, Bhat P, Hegde GR. Lehya formulations for mother and child care in Havyak community of Uttara Kannada district, Karnataka, India. Plant Science Today 2019;6(4):479-484. https://doi.org/10.14719/pst.2019.6.4.603

Copyright: ( $)$ Hegde et al (2019). This is an open-access article distributed under the terms of the Creative Commons Attribution License, which permits unrestricted use, distribution, and reproduction in any medium, provided the original author and source are credited (https://creativecommons.org/licenses/by/4.0/).

Indexing: Plant Science Today is covered by Scopus, Web of Science, BIOSIS Previews, ESCI, CAS, AGRIS, CABI, Google Scholar, etc. Full list at http://www.plantsciencetoday.online

\section{Introduction}

Traditional herbal medicine is practiced in several parts of the world particularly where large ethnic tribes and communities live. India has a great history of traditional health care and home remedies make a part of traditional medicinal system. Home remedies are generally the sole knowledge of women folk inherited from one generation to the other. In Karnataka State, Uttara
Kannada district has several ethnic communities and many people have already documented the traditional medicinal plants (1-8). Havyak community in the villages of Uttara Kannada district is one such community having sound traditional knowledge. The grandmothers of this community are treasure house of traditional medicinal knowledge as they have passed through a time when modern facilities were not available in 
the remote villages of the district. These grandmothers strongly believed that prevention is better than cure, a basic principle of Ayurveda.

Child birth is one of the important events in the life of women and is considered to be a rebirth for the mother. In rural areas when modern hospital facilities with proper drugs were not available in the past, traditional medicines would have served a number of women. Although traditional medicine in the field of mother and child health care is widely practicing in India, there are limited documentations are available

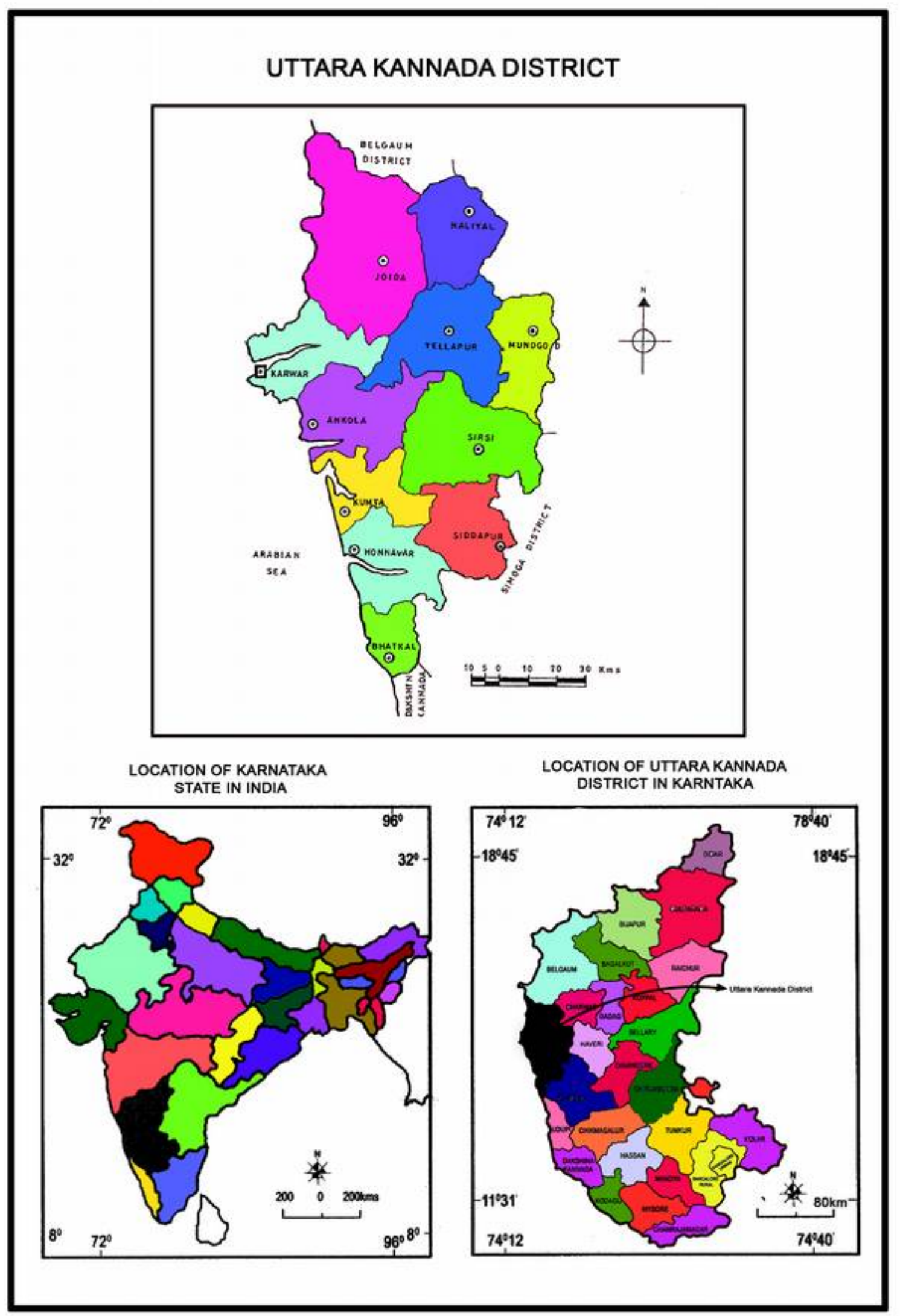

Fig. 1. Location of Uttara Kannada district in India 
about the therapeutic uses, drug preparations and administration methods of traditional formulations (9). Information about the use of medicinal plants is usually communicated orally from generation to generation and this information is at high risk of disappearing (5). Therefore, keeping in consideration of these things, the current study was designed to document the valuable knowledge from grandmothers in Havyak community of three taluks of Uttara Kannada district in the field of mother and child care.

\section{Materials and Methods}

\section{Study area}

Uttara Kannada, one of the thickly forested districts of Karnataka state, extends between $13^{\circ}$ $55^{\prime}-15^{\circ} 31^{\prime} \mathrm{N}$ latitude and $74^{\circ} 09^{\prime}-75^{\circ} 04^{\prime} \mathrm{E}$ longitude. Total area of the district is $10,291 \mathrm{~km}^{2}$ of which more than $80 \%$ constitutes part of Central Western Ghats (Fig. 1). Present work is a part of the extensive ethnobotanical survey being conducted since 2016 among grandmothers of Havyak community. The Havyak community, being chiefly areca nut growers, inhabited the forest area where infrastructures such as road, electricity, telephone facilities were not available recently. Most of the villages used to be islands for 3-4 months during the monsoon period. Any pregnant women would have been under the care of elderly people of the family who had the inherited knowledge of herbal remedies. Information about such homemade remedies for pre and postnatal mother care are collected from elderly women in Sirsi, Siddapura and Mundgod taluks of Uttara Kannada district. Elderly women above 65 years of age having the experience of more than 25 years are considered as informants.

\section{Informants' interviews and ethnomedicinal data collection}

The collection of information was through semistructured open ended interviews with questionnaire (10). Aim and objectives of the study were explained to informants in local Kannada language and data have been collected with prior consent. The objective of the study was explained to the healers. Information was collected in the local Kannada language and then translated to English. The consent of the informants was taken to share their knowledge about the plants they use to cure the diseases and then their experience in the field of treatment, causes and symptoms of the ailments they treat, average number of patients they treat per week, vernacular names, parts of the plants used and other ingredients added during the drug formulations were noted down. During the survey, depending on the convenience of the practitioner, guided field walk method was followed. A walk through the forest with the healers allowed for both confirmations of the medicinal plants they use for the treatment and the detailed information gathering. To get the consistent information on formulation each informant was interviewed more than twice and only those formulations having consistency are considered.

\section{Collection of plants, identification and preparation of voucher specimens}

The medicinal plants collected with the informants during guided field walk were authentically identified with the help of standard floras $(11,12)$ etc. The names of plant families were listed in alphabetic order. Scientific names of plant species were given according to the plant list (http://www.theplantlist.org) and the International Plant Name Index (IPNI: http://www.ipni.org). All medicinal plants recorded were photographed in the field, consequently the voucher specimens of all plants were prepared and deposited in the Museum, P.G. Department of Studies in Botany, Karnatak University, Dharwad for future reference (Shru/GRH/1-28).

\section{Quantitative ethnobotanical data analysis}

\section{Use Value (UV)}

The use value that demonstrates the relative importance of species known locally was calculated for each species was calculated using standard formula (13).

$\mathrm{UV}=\frac{\sum U i}{N}$

UV refers to the use value of species; $U_{i}$ is the number of uses; $\mathrm{N}$ is the number of informants.

\section{Relative frequency Citation (Rfc)}

The most popular medicinal plants among the traditional practitioners for mother and child care can be identified through following formula (14)

Relative frequency of citation $(\%)=$

$\frac{\text { Frequency of citation }}{\sum \text { Frequency of citation of all species }} \times 100$

Frequency of citation $(\%)=$

Number of informants whocited the medicinal plant Total number of informants interviewed $\times 100$

\section{Family Importance Value (FIV)}

Family importance value was calculated by taking the percentage of informants mentioning the family and was calculated using following formula:

$\mathrm{FIV}=\frac{F C}{N} \times 100$

FC is the frequency of citation of the family; $\mathrm{N}$ is the number of informants participating in this study (15). 


\section{Results}

\section{Medicinal plants and their uses reported by the informants}

Information was collected from 22 elderly women of the district. Data are presented in tables with botanical name, family, local name in Kannada language followed by the name of plants, parts used, mode of preparation, dose and purpose, literature reports for which it is used. The home remedies for pregnant women are in the form of paste, called "Lehya" in local language. Lehya is a semi-solid preparation of drugs, prepared with addition of jaggery, sugar or sugar-candy, ghee and boiled with prescribed medicinal plant juice or decoction. The herbal preparations included 15 lehya formulations for prenatal and postnatal care. Each formulation has 3 major ingredients. Ingredient I and II are mixture of different plant parts and prepared separately. These two ingredients are mixed with Ingredient III which contains single medicinal plant species. Ingredient III contains 15 plant species and is considered to classify the lehya into 15 different formulations. The components of 3 ingredients are given separately (Supplementary Tables 1-3).

\section{Method of preparing 'Lehya' formulations}

All the components of Ingredient I are finely ground, tied in a muslin cloth and dipped in a cup of boiling water to get decoction. This decoction is mixed with individual component of each formulations of Ingredient III, along with ghee, jaggery or sugar candy and boiled till it becomes semisolid. Components of Ingredient II are sliced or chopped, fried in ghee and added to the semisolid medium. In all, there are 15 formulations, where Ingredient I and Ingredient II are common. Lehya is recommended daily in specified quantity at early morning in empty stomach and at night after dinner. Traditional healers recommended 5 formulations each for prenatal, postnatal, for both pre and post natal care respectively.

\section{Analysis of the data}

The study revealed the use of 28 plant species belonging to 19 families which are used as components in lehya preparations. Habit-wise analysis of the plants indicates that herbs are highly used (35.71\%) followed by climbers $(28.57 \%)$ and trees $(25.00 \%)$, while shrubs are less represented (10.71\%) (Fig. 2). In most of the cases, fruits and seeds are frequently used plant parts for lehya preparations (Fig. 3). As indicated in Supplementary Table 1, UV is calculated for all the species. The plant species, Cassia sophera scored highest UV (0.77), followed by Phoenix dactylifera, Syzygium aromaticum (0.75 each), Curcuma longa (0.72) and Cocos nucifera (0.66). Plant with high UV is the indication of its importance in the traditional medicine practice as it is highly cited by many informants. Among the Relative frequency citation calculation (Rfc) it was found that Curcuma longa, Vitis vinifera, Centella asiatica and Cucumis melo var. acidulus scored the highest value (4.58\%) followed by Prunus amygdalus, Cucurbita maxima, Anacardium occidentale and Piper longum with $4.17 \%$ each (Supplementary Table 1). The most FIV values indicate the percentage of informants mentioning the plant families for the treatment of ailments. From the analysis it was found that Apiaceae, Cucurbitaceae, Leguminosae and Piperaceae are the dominant families with the FIV value $91.66 \%$, followed by Anacardiaceae, Rosaceae and Zingiberaceae (83.33\% each). The least FIV value was observed for Asparagaceae, Periplocaceae, Rubiaceae and Rutaceae (FIV=58.33\% each) (Fig. 4).

\section{Discussion}

According to humoral medicine, pregnancy is considered to be the hot state of the body, during which parturition heat is lost and the mother attains cold state. Hence, during postpartum period a lot of care is needed to restore the health of mother to equilibrium (22). Common health problems in pregnancy and postpartum are bleeding, faintness, heartburn, itching, swollen ankles, vaginal discharge, tiredness, backache, pain in perineum, wound, sexual problems etc. Traditionally mothers are supplemented with proper diet to rejuvenate the health from vulnerable state and they are strengthened physically and mentally by restricting housework, journey, maintaining proper hygiene and abstaining sexual activity (23).

The formulations of medicinal plants play major role in pre and post natal care. The plants and their preparations included in diet therapy according to the need, health status and prakriti (vata, pitta and kapha). Believing this, prenatal care in traditional practice aimed at easy delivery and healthy child, whereas postnatal care is to recover mother's health after delivery. According to traditional practitioners lehya acts as energy booster and enhancer. Some formulations of Ingredient III starts from $1^{\text {st }}$ month, $3^{\text {rd }}$ month and $5^{\text {th }}$ month and continued till $7^{\text {th }}$ month of pregnancy to enhance the good health of child and mother and to have defense against diseases. Plants used in the Ingredient I are mainly spices, which increase the body temperature and are used both in pre and post natal stages to attain the equilibrium. Plants like Centella asiatica, Trigonella foenum-graceum, Ixora coccinea, Cucumis melo are coolants and used during hot state. After delivery, mother attains the cold state; hence the plants like Citrus lemon, Cannabis sativa, Papaver somnifera etc are used. According to the informants these plants raise the core body temperature, helping to stimulate the metabolism to burn the fat accumulated and in turn allows elimination of access fluid from the body and 


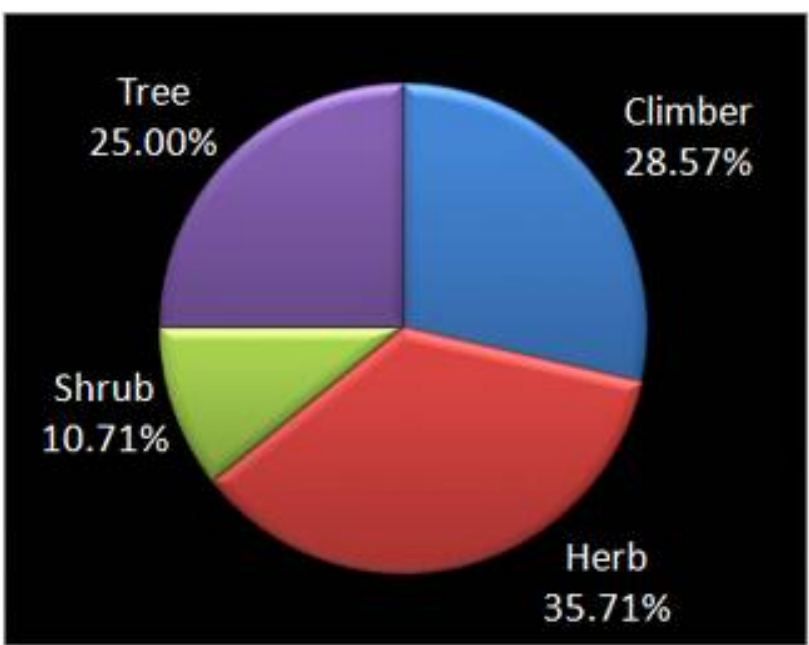

Fig. 2. Habit wise usage of the plants

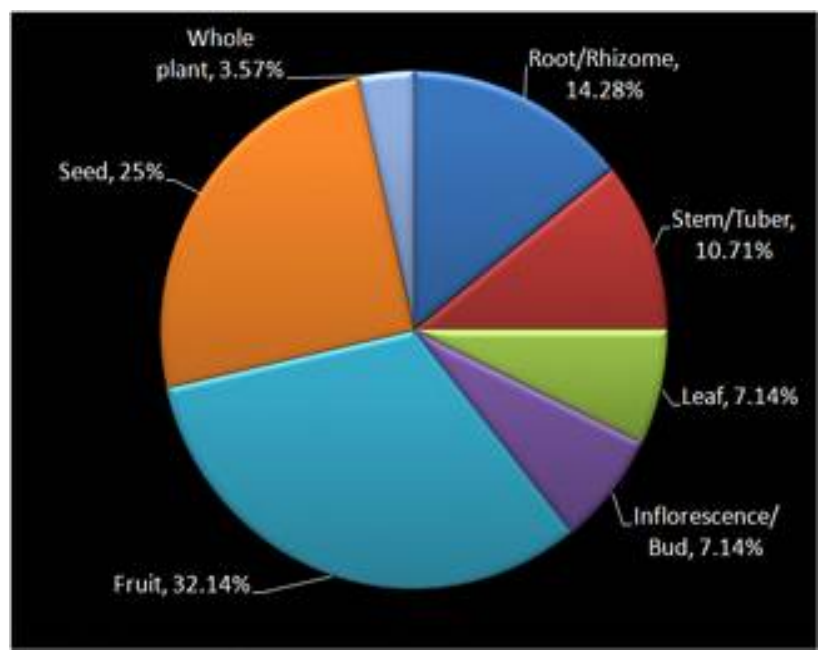

Fig. 3. Percentage of drug parts used for lehya preparation

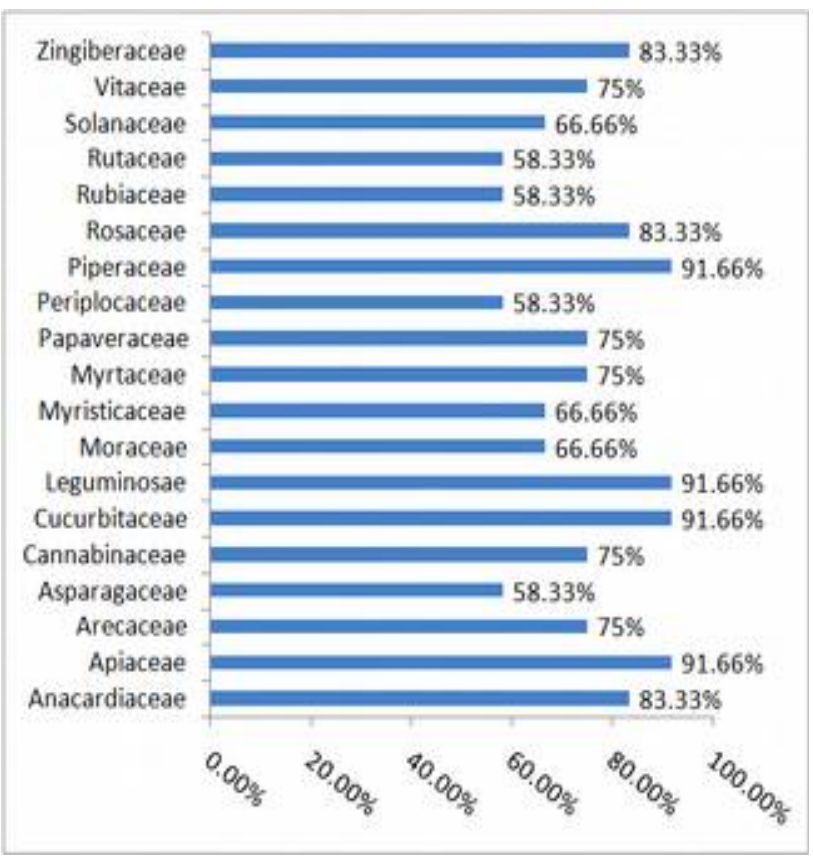

Fig. 4. Family importance value of the reported plants

maintains the equilibrium state. Sometime the formulations are prakriti (nature) based. Mother's of pitta prakriti are said to avoid the formulation of Cannabis sativa, where narcotic activity of drug may induce more heat and triggers menstruation leading to anemic condition and prescribed to have $C$. asitica, $I$. coccinia and $C$. melo. For vata prakriti Trigonella foenum-graceum is given to overcome body pain. The plants with coolant or refrigerant are not given to the patient with Kapha prakriti. Prakriti based treatment by traditional practitioners supports ayurvedic background.

Use of Asparagus racemosus tubers as galactagogue in ethno medicinal practices in Karnataka is also reported by many authors (1, 24-26). In Ayurveda it is being prescribed for urinary diseases, gynaecological disorder, hyper acidity, gastritis, as galactagogue and tonic (18). Tuber is used against body pain, swelling, abdominal and uterine pain, excessive bleeding, weakness and as a tonic along with 32 different herbs in the preparation of "battissa", to maintain hot state in mother (23). In Ayurveda Cassia sophera is used for constipation, diseases of vatam and as rejuvenator (18). In traditional practice this plant is also used for miscarriage, quick and easy delivery (27). Similarly Centella asiatica is used for smooth delivery and as a tonic (26). Root of Hemidesmus indicus as a galactogogue is in the traditional practice in Karnataka $(28,29)$. There is a mention of plants like G. glabra, V. vinifera, C. asiatica, C. longa, $Z$. officinale, $P$. longum, $P$. nigrum in Charaka Samhita for maintenance of pregnancy, cure anemia, pregnantial xerostomia, galacto purifier, control chill, suppurated umbilicus, vitiation of milk and post prandial drink. Z. officinale, $P$. longum, $P$. nigrum, $V$. vinifera are used in a preparation of Bilvadi leha, Kutajava lehya, Ashwagandhi lehya, Mravikadi lehya, Laghu cincadika lehya for physical strength, rejuvenation, tiredness and vomiting in The Ayurvedic Formulary of India.

\section{Conclusion}

In the absence of proper medical facilities in the past, all the formulations were aimed at easy delivery, healthy baby and quick recovery of mother's health. All the 15 formulations for pre and postnatal care indicate these purposes. The information provided in the study is based exclusively on the practical experience of the informants, which may help in the future studies. Research focusing on the pharmacological mechanisms and the efficacy of these formulations could provide insights that could help to improve postpartum care.

\section{Competing Interests}

The authors have no competing interests. 


\section{Authors' contributions}

SVH conducted the field visits and collected data from the informants. PB compiled the data, structured and carried out the research analysis of the work. GRH conceptualized the work plan, involved in designing the draft and approval of final manuscript.

\section{Acknowledgements}

The authors are thankful to the UGC-SAP-DRS-III, New Delhi, India for their financial assistance. Authors are also thankful to the Karnatak University, Dharwad for the facilities provided. Our special thanks are due to all the key informants of Uttara Kannada district for sharing their valuable knowledge and cooperation during data collection.

\section{References}

1. Bhandary MJ, Chandrashekhar KR, Kaveriappa KM. Medical ethnobotany of the Siddis of Uttara Kannada district, Karnataka, India. J Ethnopharmacol. 1995; 45:149-56.https://doi.org/10.1016/0378-8741(95)01274-H

2. Bhandary MJ, Chandrashekhar KR. Herbal treatment for veterinary diseases from coastal districts of Karnataka. J Econ Taxon Bot. 2003; 3:648-55.

3. Harsha VH, Shripathi V, Hegde GR. Ethnoveterinary practices in Uttara Kannada district of Karnataka. Indian J Tradit Knowl. 2005; 3:252-58.

4. Hegde VH, Hegde GR, Kholkute S. Herbal care for reproductive health: Ethnomedicobotany from Uttara Kannada district in Karnataka, India. Complement Ther Clin Pract. 2007; 13:38-45. https://doi.org/10.1016/ j.ctcp.2006.09.002

5. Achar G, Rajakumar N, Shivanna M. Ethno-medicobotanical knowledge of Khare-Vokkaliga community in Uttara Kannada district of Karnataka, India. J Complement Integr Med. 2010; 1:118.https://doi.org/10.2202/1553-3840.1324

6. Bhat P, Hegde G, Hegde GR. Ethnomedicinal practices in different communities of Uttara Kannada district of Karnataka for treatment of wounds. J $\begin{array}{lll}\text { Ethnopharmacol. } & 2012 ; & 2: 501-14\end{array}$ https://doi.org/10.1016/j.jep.2012.07.003

7. Bhat P, Hegde GR, Hegde G, Mulgund, GS. Ethnomedicinal plants to cure skin diseases-An account of the traditional knowledge in the coastal parts of Central Western Ghats, Karnataka, India. J Ethnopharmacol. 2014; 151:493-02. https://doi.org/10.1016/j.jep.2013.10.062

8. Bhat PB, Hegde S, Upadhya V, Hegde GR, Habbu PV, Mulgund GS. Evaluation of wound healing property of Caesalpinia mimosoides Lam. J Ethnopharmacol. 2016. 193:712-24. https://doi.org/10.1016/j.jep.2016.10.009

9. Nancy A. Climatic Change and Female Reproductive Health: The case of traditional medicine in Tanzania. J Pan African Stud. 2012; 5:23-35.

10. Martin G. Ethnobotany: a 'People and plants' conservation manual. Chapman and Hall, London; 1995.

11. Cooke T. Flora of Presidency of Bombay. Vols.1-3. Botanical Survey of India, Calcutta; 1967 (Reprint).
12. Saldahna CJ. Flora of Karnataka. Vols. 1 and 2. Oxford and IBH Publishers, New Delhi; 1984.

13. Albuquerque UP, Lucena RFP, Monteiro JM, Alissandra TN, Florentino, Fatima, Almeida, CBR. Evaluating two quantitative ethnobotanical techniques. Ethnobot Res Appl. 2006; 4:51-60. https://doi.org/10.17348/era.4.0.51$\underline{60}$

14. Shah A, Bharati KA, Ahmad J, Sharma MP. New ethnomedicinal claims from Gujjar and Bakerwals tribes of Rajouri-Poonch districts of Jammu and Kashmir, India. J Ethnopharmacol. 2015; 166:119-28. https://doi.org/10.1016/j.jep.2015.01.056

15. Vitalini S, Irati M, Puricelli C, Ciuchi D, Segale A, Fico G. Traditional knowledge on medicinal and food plants used in Van San Giacomo (Sondrio,Italy) an alphine ehtnobotanical study. J Ethnopharmacol. 2013; 145:517-27. https://doi.org/10.1016/j.jep.2012.11.024

16. Warrier PK, Nambiar VP, Ramankutty C. Indian medicinal plants- a compendium of 500 species. Orient Longman Publishers. 2001.

17. Jain SK. Dictionary of Indian folk medicine and ethnobotany. Deep Publications, New Delhi; 1991.

18. Yoganarasimhan SN. Medicinal Plants of India. Vols. 1 and 2. Interline Publishing Pvt. Ltd., Bangalore, Karnataka; 1996.

19. Parrotta JA. Healing plants of Peninsular India. CABI Publishers, USA. 2001.

20. Sharma RK, Dash VB. Charaka samhita. $6^{\text {th }}$ edition. Chowkhamba Sanskrit series, Varanasi, India; 1998.

21. Kirtikar KR, Basu BD. Indian Medicinal Plants. Vol.11, Oriental Enterprises, Uttaranchal; 2001.

22. Roasting ML. Smoking and Dieting: Malay Confinement in Cross-Cultural Perspective. In: The Manner Born: Birth Rites in Cross-Cultural Perspective (de L Dundes), Walnut Creek. Altamira Press; 2003.

23. Neelam J, Varsha S, Krishnan G. Therapeutic potentials of medicinal plants traditionally used during postpartum periods and their molecular targets. J Ecobiotechnol. 2011; 10:30-39.

24. Prashantkumar P, Vidyasagar G. Documentation of traditional knowledge on medicinal plants of Bidar district, Karnataka. Indian J Tradit Knowl. 2006; 3:295299.

25. Mamatha N, Pavan, Keshava MK, Venkatesh D. Data on 100 medicinal plants used by Soligas of Biligirirangana hills of Mysore district, Karnataka. My Forest. 2006; 2:121-139.

26. Kshirsagar R, Singh N. Ethnobotany of Mysore and Coorg, Karnataka State. Bishen Singh and Mahendra Pal Singh, Dehradun, India; 2007.

27. Hebbar S. Ethnomedicobotany, antimicrobial screening and pharmacognostic study of medicinal plants of Dharwad district in Karnataka. Ph.D. thesis submitted to Karnatak University, Dharwad; 2004.

28. Harsha VH, Hebbar S, Hegde GR, Shripathi V. Ethnomedical knowledge of plants used by Kunabi tribe of Karnataka in India. Fitoterapia 2002; 73:281287.https://doi.org/10.1016/S0367-326X(02)00078-3

29. Seetharam Y, Chalgeri G, Haleshi C, Vijay. Folk medicine and ethnomedicine of North-Eastern Karnataka. Ethnobotany. 1999; 11:32-37. 